\title{
SHORT REPORT: CONCOMITANT EARLY MUCOSAL AND CUTANEOUS LEISHMANIASIS IN BRAZIL
}

\author{
VIVIANE S. BOAVENTURA, VIRGINIA CAFE, JACKSON COSTA, FABIANO OLIVEIRA, ANDRE BAFICA, \\ ANDREA ROSATO, LUIZ A. R. de FREITAS, CLAUDIA BRODSKYN, MANOEL BARRAL-NETTO, AND \\ ALDINA BARRAL* \\ Centro de Pesquisas Gonçalo Moniz-Fiocruz (Fundação Oswaldo Cruz), Salvador, Bahia, Brazil; Faculdade de Medicina da Bahia \\ (Universidade Federal da Bahia), Salvador, Bahia, Brazil; Instituto de Investigação em Imunologia, São Paulo, São Paulo, Brazil
}

\begin{abstract}
Mucosal leishmaniasis (ML) is often clinically silent until reaching a highly advanced state. In this prospective study, 6 of 220 patients with early cutaneous leishmaniasis were diagnosed with mucosal involvement by otorhinolaryngological examination (a rate similar to the reported rate of late ML). Detection of early ML may represent an important strategy in preventing severe mucosal destruction in human leishmaniasis.
\end{abstract}

\section{INTRODUCTION}

Cutaneous leishmaniasis (CL) is endemic in several countries. ${ }^{1}$ Mucosal leishmaniasis (ML) usually presents as a severe form of disease affecting mainly the anterior nasal region and occasionally the pharynx and larynx. ML is potentially lethal if not adequately treated. In the majority of cases, the mucosal disease occurs after the cutaneous lesions, and the diagnosis of mucosal involvement is established only months to years after a clinical cure of the initial cutaneous site of infection. ${ }^{2} \mathrm{ML}$ is not normally recognized by the patient until partial destruction of the nose mucosa and/or cartilage occurs. ${ }^{1-4}$ Clinical diagnosis of the early-stage mucosal disease is uncommon and is generally a casual finding observed during routine physical examination of patients with current or past cutaneous lesions. There are few reported cases of mucosal lesions that are detected at the same time as the initial cutaneous lesion, ${ }^{5}$ and the frequency of such cases is unknown. In this study, we performed a careful otorhinolaryngological examination in 220 consecutive CL cases as a strategy for early ML detection.

\section{MATERIALS AND METHODS}

Patients and clinical evaluation. From November 2000 to June 2002, 220 consecutive patients with CL were evaluated at our field clinic in the municipality of Jequié (Bahia State). All patients were submitted to physical examination, including dermal and otorhinolaryngological exams. The diagnostic criteria for CL included clinical examination, Montenegro skin test (MST), serology, histopathological evaluation, and parasite isolation. After anterior rhinoscopy, oropharynx exam, and mirror laryngoscopy, patients with suspicious lesions were submitted for a fiberoptic exam. Patients with active primary localized CL (without scar from a previous cutaneous infection) and with simultaneous and distant mucosal involvement (hyperemia, edema, erosion, and/or granulomatous aspect at the oral, pharyngeal, and/or laryngeal mucosa) were classified as a concomitant mucocutaneous form. Cases of concomitant disease were confirmed by the presence of Leishmania at the mucosal site (immunohistochemistry and parasite isolation in hamsters) as well as by clinical response to antimonial therapy. Patients were treated with antimoni-

\footnotetext{
* Address correspondence to Aldina Barral, Centro de Pesquisas Gonçalo Moniz, Rua Waldemar Falcão, 121, Candeal CEP 40296-710 Salvador, Bahia, Brazil. E-mail: abarral@cpqgm.fiocruz.br.
}

ate- $n$-methyl-glucamine (20 $\mathrm{mg} / \mathrm{Sb} / \mathrm{kg} / \mathrm{d}$ for 30 days).The study was approved by the Gonçalo Moniz Research Center (CPqGM/FIOCRUZ-Bahia) Institutional Review Board, and informed consent was obtained before enrollment in the study.

Diagnostic procedures. Montenegro skin test. The test was performed as previously described. ${ }^{6}$ Briefly, $0.1 \mathrm{~mL}$ of antigen $(250 \mathrm{mg} / \mathrm{mL}$ of protein) was applied intradermically into the anterior face of the left forearm. The diameter of the induration (in $\mathrm{mm}$ ) was determined 48 hours after inoculation. Reactions with a diameter $\geqslant 5 \mathrm{~mm}$ were considered positive. $^{6}$

Serology. Anti-leishmania antibody titers were determined by indirect immunofluorescence. ${ }^{7}$ In brief, 96-well microtiter plates (Probind; Falcon, Becton Dickinson, Lincoln Park, NJ) were coated with soluble leishmanial antigen (SLA) from $L$. braziliensis by overnight incubation at $4^{\circ} \mathrm{C}$. Then, sera $(1: 100)$ were added for 30 minutes at room temperature, followed by incubation with alkaline phosphatase-conjugated anti-human IgG antibody (Sigma Immunochemicals, St. Louis, MO). Next, plates were developed using a chromogenic solution of $p$-nitrophenylphosphate, and absorbance was recorded at $405 \mathrm{~nm}$.

Biopsy sample collection. Biopsies of the nasal and/or oral mucosal lesions were performed under local anesthesia with Lidocain spray (10\%) or Lidocain (2\%) with vase-constrictor, using either forceps or Takahashi tweezers (Storz Instruments, St. Louis, MO). Tissues were preserved in $10 \%$ formalin for histopathologic analysis.

Histopathology and immunohistochemistry. Fixed tissue material was processed and stained by Hematoxylin Eosin Stain (H\&E). For immunohistochemistry, endogenous peroxidase was blocked using a $3 \% \mathrm{H}_{2} \mathrm{O}_{2}$ solution, followed by incubation with $10 \%$ skim milk. Sections were incubated for 16 hours at $4{ }^{\circ} \mathrm{C}$ with rabbit anti-Leishmania (primary antibody; $1: 1,500)$, and biotin-labeled anti-rabbit $\operatorname{IgG}(1: 1,500$; Sigma) was used as a secondary antibody. Then, streptavidinhorse radish peroxidase (1:2,000; Sigma) complex was added, and samples were detected using the substrate diaminobenzidine (DAB; Sigma) followed by Harris hematoxylin counterstaining as previously described. ${ }^{8}$

Culture. Parasites were isolated from biopsy material after hamster inoculation as described elsewhere. ${ }^{9}$

DNA extraction and polymerase chain reaction. DNA extraction of biopsies was performed with the Kit Nucleon HT (Pharmacia Biotech, Piscataway, NJ) according to the manu- 
facturer's instructions. Polymerase chain reaction (PCR) was performed as previously described. ${ }^{10}$

\section{RESULTS}

Six of 220 patients diagnosed with CL concomitantly presented with ML disease (3 men and 3 women; mean age, 36 years). Table 1 summarizes the clinical data from these patients. None of them had a prior history of leishmaniasis or presented with a cutaneous scar. Mucosal lesions were restricted to the nose in five patients, and the otorhinolaryngological examination revealed localized lesions with hyperemia, edema, erosion, and/or granulomatous aspect, but without destruction of the anterior nasal cartilage (Figure 1). Only one patient presented with pharyngeal and laryngeal involvement and had a nasal septal perforation. All concomitant mucocutaneous patients had four or fewer lesions on their extremities and/or face, and four of them had $<30$ days of cutaneous disease (Table 1). Regional lymphadenopathy was present in four of six concomitant patients with leishmaniasis. Lymphadenopathy was not predictive of mucosal lesions. In two patients, lymph nodes were cervical; in the others, lymph nodes were axillary and inguinal.

None of the 214 patients with only CL presented with any mucosal lesions. Five concomitant patients with CL and ML were biopsied. One patient did not consent to the biopsy procedure, and this case was confirmed by clinical examination, serology, MST, and clinical response to antimonial therapy (Table 1, patient E). There was no case of other concomitant infection or mucosal disease, and none of the patients had a history of intranasal cocaine use. None of them had immunosuppressive conditions, and the lesions healed with medical treatment.

MST was negative in only one patient whose first cutaneous lesion had appeared only 20 days before examination. This patient's serological exam was positive, and large numbers of parasites were visible on the histopathological and immunohistochemical examinations. Anti-leishmania antibody titers

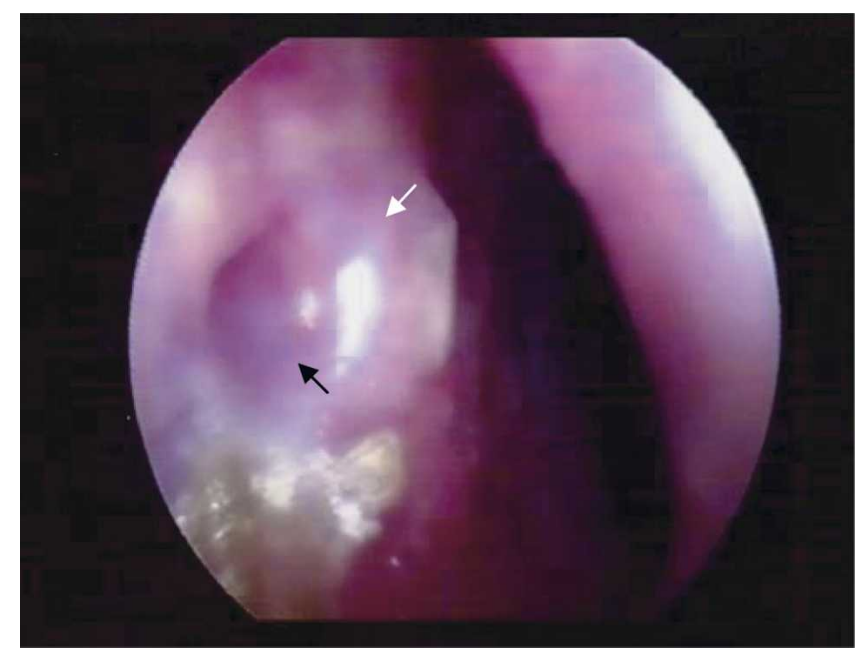

FIGURE 1. Nasal endoscopic view of mucosal leishmaniasis: mucosal erosion (black arrow), edema, and hyperemia (white arrow) of the nasal septum. This figure appears in color at www.ajtmh.org.

were positive in $60 \%$ of the concomitant patients with CL and ML.

Parasites were detected by histopathology and immunohistochemistry in tissue samples from three of five concomitant patients with CL and ML. Parasites from four patients with ML concomitant leishmaniasis were isolated by culture, and this resulted in a positive diagnosis in all of these patients. Parasite strains were characterized as Leishmania braziliensis by PCR.

\section{DISCUSSION}

The finding of initial stage mucosal leishmaniasis is unusual, considering the usually late diagnosis of the disease. Early mucosal lesions were previously described as a slight edematous swelling and reddening, as well as ulcers of the

TABLE 1

Description of the patients according to sex, age, number, and location of cutaneous lesion, time of cutaneous disease, location, and characteristics of the mucous lesion and complementary exams (Montenegro skin test, serology, histopathology with immunohistochemistry and parasite isolation)

\begin{tabular}{|c|c|c|c|c|c|c|c|c|}
\hline Patient & $\underset{\text { (years)/sex }}{\begin{array}{c}\text { Age } \\
\text { sex }\end{array}}$ & $\begin{array}{l}\text { Number and location of } \\
\text { cutaneous lesions }\end{array}$ & $\begin{array}{l}\text { Time with } \\
\text { disease }\end{array}$ & Location and characteristic of mucosal lesion & MST & $\begin{array}{c}\text { Serology } \\
\text { IFI }\end{array}$ & $\begin{array}{l}\text { Histopathology/ } \\
\text { IMH }\end{array}$ & $\begin{array}{l}\text { Parasite } \\
\text { isolation }\end{array}$ \\
\hline A & $24 / \mathrm{F}$ & $\begin{array}{l}\text { Three } \\
\text { Right upper limb }\end{array}$ & 30 days & $\begin{array}{l}\text { Septum and left inferior turbinate/ } \\
\text { edema and erosion }\end{array}$ & ++++ & Negative & Positive & Positive \\
\hline B & $35 / \mathrm{M}$ & $\begin{array}{l}\text { One } \\
\text { Left lower limb }\end{array}$ & 20 days & $\begin{array}{l}\text { Anterior nasal septum and right } \\
\text { inferior turbinate/edema and } \\
\text { erosion }\end{array}$ & Negative & $1 / 80$ & Positive & Positive \\
\hline $\mathrm{C}$ & $52 / \mathrm{M}$ & $\begin{array}{l}\text { Two } \\
\text { Left lower limb }\end{array}$ & 08 months & $\begin{array}{l}\text { Anterior septum, left inferior } \\
\text { turbinate, oral cavity, pharynx, } \\
\text { larynx/granulomatous aspect, } \\
\text { mucosal ulceration and edema, } \\
\text { nasal septal perforation }\end{array}$ & ++ & $1 / 160$ & Negative & Positive \\
\hline $\mathrm{D}$ & $19 / \mathrm{F}$ & $\begin{array}{l}\text { One } \\
\text { Right lower limb }\end{array}$ & 15 days & $\begin{array}{l}\text { Inferior turbinates/small erythematous } \\
\text { lesions }\end{array}$ & ++ & Negative & Negative & Positive \\
\hline $\mathrm{E}$ & $16 / \mathrm{F}$ & $\begin{array}{l}\text { Four } \\
\text { Frontal region } \\
\quad \text { and limb }\end{array}$ & 20 days & $\begin{array}{l}\text { Anterior nasal septum and inferior } \\
\text { turbinate/hyperemia, edema and } \\
\text { erosion }\end{array}$ & ++ & $1 / 80$ & $\mathrm{NP}$ & NP \\
\hline $\mathrm{F}$ & $71 / \mathrm{M}$ & $\begin{array}{l}\text { One } \\
\text { Left lower limb }\end{array}$ & 08 months & $\begin{array}{l}\text { Anterior nasal septum/hyperemia and } \\
\text { granulomatous aspect }\end{array}$ & + & NP & Positive & NP \\
\hline
\end{tabular}


septum's mucosa and inferior cornet..$^{3,4,11}$ Here, we have shown that four of six patients presented with concomitant mucosal and cutaneous disease with $<30$ days of disease progression. In addition, these patients displayed mucosal lesions similar to those reported by others ${ }^{3,4,11}$ (Figure 1). To our knowledge, this is the first endoscopic image documentation of an early mucosal lesion caused by L. braziliensis. All the patients were followed up for 5-11 months after treatment, and we did not observe any active mucosal lesions after antimonial therapy.

Simultaneous CL and ML lesions were previously described by others. ${ }^{1,3,4,11-13}$ Nevertheless, these studies did not report if the cutaneous ulcers were the primary site of infection. In that case, secondary cutaneous lesions caused by reactivation or reinfection were also probably included. . $^{1,4,11-13}$ Furthermore, most of these reports did not show the presence of parasites, reinforcing the idea that advanced cases of ML were largely represented in that series of patients. We obtained a high level of positive parasite detection, which is in sharp contrast to the difficulty in isolating parasites from late mucosal disease. ${ }^{1-3,5,14}$ Although parasites have not been typed in all $220 \mathrm{CL}$ cases, we and others have previously shown that L. braziliensis is highly prevalent in the field study area. ${ }^{13,15}$

In 1922, Klotz and Lindenberg ${ }^{5}$ studied four concomitant patients with primary CL and ML and suggested that, to detect early stages of mucosal lesion, a systemic search of the nose must be made in all cases of skin leishmaniasis. In contrast to our study, they found parasitological confirmation in only one patient. A possible explanation for these differences is that, in addition to the isolation of Leishmania parasites after inoculation in hamsters, we used PCR, a highly sensitive method for diagnosis of CL and ML cases. ${ }^{10,16}$

In this series, the prevalence of concomitant cutaneous and mucosal disease at the initial simultaneous manifestation of leishmaniasis was $2.7 \%$. It is possible that many cases of cutaneous disease later involving mucosal lesions had already presented nasal alterations at the time of diagnosis of the primary lesions. The identification of those cases shows the importance of routine evaluation of the nasal mucosa in all patients with CL and suggests that metastatic mucosal lesions can already be identified during primary cutaneous disease.

Received December 20, 2005. Accepted for publication April 25, 2006.

Financial support: This study was supported by CNPq (Conselho Nacional de Desenvolvimento Científico e Tecnológico) and FAPESB (Fundação de Amparo à Pesquisa do Estado da Bahia) grants. V.B. received doctorate fellowship from CAPES (Coordenação de Aperfeiçoamento de Pessoal de Nível Superior), Brazil. A.B., J.C. and M.B-N. are senior investigators from CNPq. We thank Eliane Gocs Nascimento and members of the Centro de Referéncias para Doenças Endémicas Pirajá da Silva for support in endemic area.

Disclosure: There are no commercial or other associations that might pose a conflict of interest.

Authors' addresses: Vivane S. Boaventura, Virginia Cafe, Jackson Costa, Fabiano Oliveira, Andre Bafica, Andrea Rosato, Luiz A. R. de Freitas, Claudia Brodskyn, Manoel Barral-Netto, and Aldina Barral, Centro de Pesquisas Gonçalo Muniz Rua Waldemar Falcào, 121 Candeal, CEP 40296-710, Salvador, Bahia, Brazil.
Reprint requests: Prof. Aldina Barral, Centro de Pesquisas Gonçalo Moniz, Rua Waldemar Falcão, 121, Candeal CEP 40296-710 Salvador, Bahia, Brazil. E-mail: abarral@cpqgm.fiocruz.br.

\section{REFERENCES}

1. Marsden PD, 1986. Mucosal leishmaniasis ("espundia" Escomel, 1991). Trans R Soc Trop Med Hyg 80: 859-876.

2. Zajtchuk JT, Casler JD, Netto EM, Grogl M, Neafie RC, Hessel CR, De Magalhaes AV, Marsden PD, 1999. Mucosal leishmaniasis in Brazil. Laryngoscope 99: 925-939.

3. Pessoa SB, Barreto MP, 1948. Leishmaniose Tegumentar Americana. Rio de Janeiro: Serviço de Documentação do Ministério da Educação e Saúde. Imprensa Nacional.

4. Klotz O, Lindenberg H, 1922. The pathology of leishmaniosis of the nose. Am J Trop Med 3: 117-141.

5. Villela F, Pestana BR, Pessoa SB, 1936. Presença de Leishmania braziliensis na mucosa nasal sem lesão aparente em casos recentes de leishmaniose cutânea. Hospital (Rio J) 16: 953-960.

6. Reed SG, Badaró R, Masur H, Carvalho EM, Lorenço R, Lisboa A, Teixeira R, Johnson WD, Jones TC, 1986. Selection of a skin test antigen for American visceral leishmaniasis. Am J Trop Med Hyg 35: 79-85.

7. Cuba Cuba CA, Marsden PD, Barreto AC, Rocha R, Sampaio RP, Patzlaff L, 1980. Parasitologic and immunologic diagnosis of American cutaneous leishmaniasis. Bol Oficina Sanit Panam 89: 195-208.

8. Barral A, Pedral-Sampaio D, Grimaldi Junior G, Momem H, Mcmahon-Pratt D, Jesus AR, Almeida R, Badaró R, BarralNetto M, Carvalho EM, Johnson WD, 1991. Leishmaniasis in Bahia, Brazil: Evidence that Leishmania amazonensis produces a wide spectrum of clinical disease. Am J Trop Med Hyg 44: 536-546.

9. Faber WR, Oskam L, Van Gool Kroon NC, Knegt-Junk KJ, Hofwegen H, Van Der Wal AC, Kager PA, 2003. Value of diagnostic techniques for cutaneous leishmaniasis. J Am Acad Dermatol 49: 70-74.

10. Oliveira JG, Novais FO, de Oliveira CI, da Cruz Junior AC, Campos LF, da Rocha AV, Boaventura V, Noronha A, Costa JM, Barral A, 2005. Polymerase chain reaction (PCR) is highly sensitive for diagnosis of mucosal leishmaniasis. Acta Trop 94: $55-59$.

11. De Oliveira MR, Macedo VO, De Carvalho EM, Barral A, Marotti JG, Bittencourt A, De Abreu MVA, Orge MGO, Lessa HA, Marsden PD, 1995. Estudo evolutivo da leishmaniose mucosa (7 a 17 anos de seguimento) causada por Leishmania (Viannia) braziliensis em Três Braços, Bahia. Rev Soc Bras Med Trop 28: 325-332.

12. Osorio LE, Castillo CM, Ochoa MT, 1998. Mucosal leishmaniasis due to Leishmania (Viannia) panamensis in Colombia: Clinical characteristics. Am J Trop Med Hyg 59: 4-52.

13. Jones TC, Johnson WD Jr, Barretto AC, Lago E, Badaro R, Cerf B, Reed SG, Netto EM, Tada MS, Franca TF, Wiese K, Golightly L, Fikrig J, Costa JML, Cuba CC, Marsden PD, 1987. Epidemiology of American cutaneous leishmaniasis due to Leishmania braziliensis braziliensis. J Infect Dis 56: 73-83.

14. Marsden PD, Llanos-Cuentas EA, Lago EL, Cuba CC, Barreto AC, Costa JM, Jones TC, 1984. Human mucocutaneous leishmaniasis in Três Braços, Bahia-Brazil. An area of Leishmania braziliensis braziliensis transmission. III Mucosal disease. Presentation and inicial evolution. Rev Soc Bras Med Trop 17: 179-186.

15. Schriefer A, Schriefer AL, Goes-Neto A, Guimaraes LH, Carvalho LP, Almeida RP, Machado PR, Lessa HA, de Jesus AR, Riley LW, Carvalho EM, 2004. Multiclonal Leishmania braziliensis population structure and its clinical implication in a region of endemicity for American tegumentary leishmaniasis. Infect Immun 72: 508-514.

16. de Oliveira CI, Bafica A, Oliveira F, Favali CB, Correa T, Freitas LA, Nascimento E, Costa JM, Barral A, 2003. Clinical utility of polymerase chain reaction-based detection of Leishmania in the diagnosis of American cutaneous leishmaniasis. Clin Infect Dis 37: 149-153. 